\title{
Effects of some non-genetic factors on concentration of urea in milk in Polish Holstein-Fresian cows
}

\author{
K. Rzewuska and T. Strabel ${ }^{1}$ \\ Poznan University of Life Sciences, Faculty of Animal Breeding and Biology, \\ Department of Genetics and Animal Breeding, Wołyńska 33, 60-637 Poznań, Poland
}

KEY WORDS: dairy cattle, milk urea, lactation curve, environmental factors

Received: 7 June 2012

Revised: 30 July 2013

Accepted: 2 September 2013
${ }^{1}$ Corresponding author:

e-mail: strabel@jay.up.poznan.pl

\begin{abstract}
The objective of this study was to estimate lactation curves of milk urea concentration for primiparous Polish Holstein-Friesian cows, milked in different months and air temperatures, using random regression test-day models. In the study, 6086431 test-day records collected in the years 2001 to 2009 from 900962 cows were analysed. Regression curves in classes of environmental effects were modeled with Legendre polynomials. The pattern of lactation curves for milk urea (MU) resembled the lactation curve for milk. In summer and early fall, the MU concentration was higher than in the winter months. At the same time, the increase in the MU concentration was even more strongly associated with the increase of temperature, also in the winter months. In herds with higher milk production, the MU concentration was also higher, however, interaction between average herd milk production and month-temperature was found. A greater influence of month and air temperature was observed in herds with low milk production.
\end{abstract}

\section{Introduction}

The concentration of urea in milk (MU) is used to evaluate the protein-energy balance in the ration and as an indicator of the energy status of a cow. The latter can be the underlying cause of metabolic problems and deterioration of fertility, especially in early lactation of high-producing cows. Identification of energy balance problems solely on the basis of MU is inaccurate because of the large variability of this trait. The coefficient of variation of milk urea nitrogen (MUN) exceeds 30\% (Stoop et al., 2007; Bastin et al., 2009). Furthermore, nutrition is the main, but not only, factor influencing the urea concentration in milk. Physiology changes with the lactation trajectory, environmental factors such as milk yield, month of the year, time of day, and successive parities also have a significant impact on MUN (Godden et al., 2001; Wattiaux et al., 2005). Milk urea concentration is also genetically determined. Average daily heritability ranges from 0.13 to 0.39 for the first lactation (Miglior et al., 2007; Bastin et al., 2009).

The multitude of factors affecting MUN is a source of misinterpretation of the MUN concentration in relation to dietary composition. To avoid wrong management decisions taken on the basis of MUN concentrations, it is important to analyse them in connection with other genetic and non-genetic factors. Production season is among the major factors that are a source of this variability. The results of some studies suggest that a higher MUN concentration is observed in the summer months (Godden et al., 2001; Arunvipas et al., 2003; 
Hojman et al., 2004; Wattiaux et al., 2005; Bastin et al., 2009). The same relation was reported by Rajala-Schultz and Savile (2003), but only for lowproduction herds. This can be due to a high content of degradable protein in pasture or mowburn of silage, which intensifies proteolysis. Hojman et al. (2004) suggested, however, that seasonal changes of MU cannot be explained by changes in the feeding programme since the analysed herds were fed with a total mixed ration (TMR) of relatively constant composition throughout the year.

Seasonal variation can be associated with many environmental factors, such as temperature or daylight, nutrient factors like grazing, water intake, or feed quality, and management factors such as calving pattern throughout the year (Godden et al., 2001; Wattiaux et al., 2005). Rajala-Schultz and Savile (2003) claimed that heat stress influences the MUN concentration in summer because of a lower dry matter intake (DMI) and higher requirement for energy needed for thermoregulation.

Two main herd environmental factors that determine cow production are feeding and management. In herds with a high milk production, higher MUN concentration with smaller standard deviation was shown by Rajala-Schultz and Savile (2003). This can arise from the positive correlation between milk yield and MUN (Jonker et al., 1998; Arunvipas et al., 2003; Johnson and Young, 2003; Hojman et al., 2004; Cao et al., 2010) or feeding management, which influences both milk production and MUN concentration.

Daily changes MUN concentration on successive days in milk are illustrated by lactation curves. Their shape differs depending on the population. Some authors have found that the MUN curve resembled a lactation curve for milk yield with a peak between the second and third month and decreased thereafter (Jonker et al., 1998; Stoop et al., 2007). In other studies, the curve for MUN had a mirror shape, resembling protein and fat percentage curves (Hojman et al., 2004; Miglior et al., 2006; Ramirez et al., 2007).

Large variability and the multitude of factors influencing MUN require precision when taking them into account. The use of daily observations permits accurate analysis. The test-day model (TDM) can describe the shape of lactation curves specific for a group of cows belonging to the same class of a given environmental effect, for example for cows milked in the same month with the same air temperature.

The objective of this study was to use the TDM to investigate the influence of environmental factors such as month-temperature and average herd milk production on lactation curves of urea concentration in milk of primiparous Polish Holstein-Friesian cows.

\section{Material and methods}

A total of 8095230 records from Polish Holstein-Friesian cows in first lactation collected in the years 2001-2009 was available for this study. Milk urea concentration was measured in accredited milk quality laboratories by infrared spectrometry, using Combifoss-Milkoscans with a range of 100-1000 $\mathrm{mg} \cdot \mathrm{l}^{-1}$ and was not converted to milk urea nitrogen (MUN) because this is the form of phenotypic information that is sent back to dairy farmers. If days in milk (DIM) were fewer than 5 and greater than 305, the data was removed. All records for lactation initiated by abortion were also deleted. Edits included restriction for the range of milk urea concentration between 12 and $629 \mathrm{mg} \cdot \mathrm{l}^{-1}$, minimum of 5 or 4 records per lactation when milk samples were collected once per month or once per two months, respectively. The final edited data set used in this study consisted of 6086431 test day records from 900962 primiparous cows milked in 24553 herds. Data on feeding and housing systems in these herds were not available because they are not routinely collected. The average number of cows in milk on a test day in a herd was $9.9(\mathrm{SD}=19.8)$ and throughout the studied period the average number of cows per herd was 37.2 ( $\mathrm{SD}=94.0)$. Two classes of age at calving were defined: 18-23 (over 1 million records) and 24-33 months (over 5 million records). The second class was not divided into smaller ones because initial studies showed lack of statistically significant differences. The average daily milk production level for each herd (MP) in three 3-year periods was calculated. A minimum of 50 records for each period was required. Three classes of herd production levels were created: below 20 (almost 4 million records), 20-25 (0.8 million records) and above $25 \mathrm{~kg}$ milk per day (1.2 million records). The mean environmental temperature was calculated for each month in each year based on measurements from seven weather stations located in those regions of Poland where cows are kept. Ten temperature classes were created, with 3-degree intervals, starting from $-7.9^{\circ} \mathrm{C}$. The season when milk samples were collected was described as a month of the year with a given average temperature, which enabled accounting for the interaction between month and temperature. Not all temperature classes were observed in each month of the year, therefore 
34 classes of month-temperature were created (the smallest class contained over 42 thousand records). Based on 3 classes of herd production level and 34 classes of month-temperature, 102 classes of interaction between these effects were created (with 0.9 million records in the smallest class). During the initial analyses, environmental factors and their interactions were tested with the GLM procedure using SAS (1990).

Three models were structured so that the solutions could be estimated separately for each DIM in each class of month-temperature (MT), herd average daily milk production level (MP) and herd production level-month-temperature (PMT), respectively.

The month-temperature model was:

$$
\begin{aligned}
& Y_{i j k l m}=h t d_{i}+A G E_{j}+\sum_{n=1}^{4} b_{k n} z_{m n l}+ \\
& +\sum_{n=1}^{3} a_{m n} z_{m n l}+\sum_{n=1}^{3} p_{m n} z_{m n l}+e_{i j k l m}
\end{aligned}
$$

where: $Y_{i j k l m}$ - the milk urea concentration on TD $l$ of cow $m$ within herd-test-day effect $i$ belonging to $j$ class of age at calving, milked in $k$ class of monthtemperature (MT), $h t d_{i}$ - the random herd-test-day effect, $b_{k n}$ - fixed regression coefficient specific for $k$ month-temperature class, $a_{m n}$ - the genetic random regression coefficient specific for the animal effect (AG) of cow $m, p_{m n}$ - the random permanent environmental (PE) effect, $e_{i j k l m}$ - the residual effect for each observation. The $z_{m n l}$ - Legendre polynomials on DIM. The lactation curves for month-temperature were modeled using Legendre polynomials of the third order, and for AG and PE, of the second order.

The herd milk production model was:

$$
\begin{aligned}
Y_{i j k l m o} & =h t d_{i}+A G E_{j}+P x M T_{o}+\sum_{n=1}^{4} c_{k n} z_{m n l}+ \\
& +\sum_{n=1}^{3} a_{m n} z_{m n l}+\sum_{n=1}^{3} p_{m n} z_{m n l}+e_{i j k l m o}
\end{aligned}
$$

where: $Y_{i j k l m o}$ - the TD milk urea concentration on TD $l$ of cow $\mathrm{m}$ within herd-test-day effect $i$ belonging to $j$ class of age at calving, milked in $o$ class of production level-month-temperature, from a herd with an average daily milk production level (MP) $k$, $P x M T$ - fixed effect of $o$ production level - month temperature, $c_{k n}$ - fixed regression coefficients specific for $k$ herd production level. The other effects were defined as in the first model.

The herd milk production-month-temperature model was:

$$
\begin{aligned}
& Y_{i j k l m}=h t d_{i}+A G E_{j}+\sum_{n=1}^{4} d_{k n} z_{m n l}+ \\
& +\sum_{n=1}^{3} a_{m n} z_{m n l}+\sum_{n=1}^{3} p_{m n} z_{m n l}+e_{i j k l m}
\end{aligned}
$$

where: $Y_{i j k l m}$ - the TD milk urea concentration on TD $l$ of cow $m$ within herd-test-day effect $i$ belonging to $j$ class of age at calving, milked in $k$ class of production level-month-temperature, $d_{k n}$ - fixed regression coefficients specific for $k$ herd production level-month-temperature class (PMT), $e_{i j k l m}-$ the residual effect for each observation. The other effects were defined as in the previous models.

To solve the mix model equations (MME), the BLUP method was employed with the use of the preconditioned conjugate gradient algorithm that iterates on data (Misztal et al., 2002). Lactation curves for each fixed effect were plotted based on obtained solutions for the largest class with over 0.4 million records. These classes were formed by cows calving at 24-33 months of age in April with a temperature between $7.1^{\circ} \mathrm{C}$ and $10^{\circ} \mathrm{C}$. (Co)variance components, necessary to solve MME, were estimated by the Restricted Maximum Likelihood Method (Misztal et al., 2002), based on records of 10200 cows from 50 randomly selected herds with a minimum of 50 first lactations each.

\section{Results and Discussion}

\section{Level of MU concentration and effect of stage of lactation}

The average milk urea concentration for cows in first parity was $211.9 \mathrm{mg} \cdot 1^{-1}$ (SD 98.6), which is lower than the mean value reported by most researchers, which ranges for milk urea nitrogen $\left(\mathrm{MU} \mathrm{mg} \cdot \mathrm{l}^{-1}=21.4 \times \mathrm{MUN} \mathrm{mg} \cdot \mathrm{dl}^{-1}\right.$ ) between 12 and $21 \mathrm{mg} \cdot \mathrm{dl}^{-1}$ (Johnson and Young, 2003; Wattiaux et al., 2005; Stoop et al., 2007; Bastin et al., 2009) but close to levels observed in Canadian (Miglior et al., 2006) and Israeli (Ramirez et al., 2007) populations. The coefficient of variation was very high and stable for all test days, ranging from $44 \%$ to $48 \%$. The lowest level of MU was observed at the beginning of lactation. After calving, the daily MU decreased sharply, reaching a nadir in the second week, which was not reflected in estimated lactation curves. In the following months the MU level subsequently increased, reaching a peak in the 5th month of lactation and started to decrease thereafter until its end. The lowest MUN in the first month of lactation is in line with the results of other authors (Arunvipas et al., 2003; Johnson and Young, 2003; RajalaSchultz and Saville, 2003; Miglior et al., 2006; Cao et al., 2010), who suggest this is due to lower decrease in DMI. A low level of MU after calving can be related to the quality of protein in the diet. 
For this group of cows, protein with low rumen degradation is recommended. The maximum MU concentration in mid-lactation with a similar shape of the lactation curve was reported previously in populations with milk production higher than in our study (16.9 kg per day) and originating from various climates (Arunvipas et al., 2003; Jilek et al., 2006; Cao et al., 2010). In contrast, Ramirez et al. (2007) reported a gradual increase of MUN with advancing DIM from the $2^{\text {nd }}$ month of lactation, achieving a maximum value at the end of lactation. We have no explanation for such diverse shapes of the MU lactation curves in various countries. In our study, the peak MU concentration occurred later than the peak of milk production ( $2^{\text {nd }}$ month of lactation, results not shown) and the lactation curve for MU was more persistent than that for milk. A similar trend throughout lactation is characteristic for DMI. Depression in feed intake is typical for the early postpartum period after which DMI increases until midlactation. It is possible that the demand for protein decreases and the composition of a ration changes after the peak of milk production. If the energy concentration drops, the relative protein intake increases, which can affect the MU level.

The reports sent to Polish farmers present the mean MU for four stages of lactation. The first two periods, important due to the occurrence of metabolic disorders, are below 40 DIM and between 41 and 100 DIM. In the first period, we observed the minimum values and the beginning of increases in MU concentration. The second period covered the highest changes in milk urea concentrations. The difference between minimum and maximum levels of MU on particular test days was rather large $\left(46.8 \mathrm{mg} \cdot \mathrm{l}^{-1}\right)$. For that reason, the average values for groups of cows, and the second group in particular, are less informative because of heterogeneity. Unfortunately, this limits their usefulness in evaluation of diet composition. As it has been shown that $\mathrm{MU}$ is a heritable trait, consequently, a known individual animal's potential to produce MU on a certain level may further help in indicating nutritional problems.

\section{Effect of month and temperature}

The mean MU values were associated with the month of the year. The urea concentration in milk tended to be higher during the summer and early fall (from July to October), with a maximum value in August $\left(237.0 \mathrm{mg} \cdot \mathrm{l}^{-1}\right.$ ) and elevated level in May and June $\left(213.8 \mathrm{mg} \cdot \mathrm{l}^{-1}\right)$. The lowest MU was observed in winter months (192.2 $\mathrm{mg} \cdot \mathrm{l}^{-1}$ in January). There is no consistent pattern in MU changes between months in the studies of different authors, but they generally report that the greatest concentration can be observed during the summer months (Godden et al., 2001; Arunvipas et al., 2003; Hojman et al., 2004; Wattiaux et al., 2005; Bastin et al., 2009). Only in the Canadian population were low MU concentrations observed not only during the winter but also, for example, in June (Arunvipas et al., 2003; Miglior et al., 2007).

The range in month means amounted to $44.8 \mathrm{mg} \cdot \mathrm{l}^{-1}$ and was similar to the range of differences observed in lactation trajectory. Feed changes during the year, such as use of a different silage or fresh silage, can influence the MU concentration. Elevated levels of MU in late spring/ early summer observed in our study can be influenced by the calving pattern throughout the year, the highest milk production in these months as well as high concentration of degradable protein in fresh grass. Nutrition, a seasonal factor, can be confounded by air temperature, whose pattern is consistent with MU level, lower in winter and higher in summer months. Association between calendar month and environmental factors, including air temperature, was also indicated by Godden et al. (2001) and Wattiaux et al. (2005). In our study, we observed a positive correlation between MU and temperature. The MU concentration increased by $1.89 \mathrm{mg} \cdot \mathrm{l}^{-1}$ as temperature increased by $1^{\circ} \mathrm{C}$ per day. The average MU values were 171.9 and $235.2 \mathrm{mg} \cdot \mathrm{l}^{-1}$ for the classes with the lowest and highest temperature, respectively. High MU concentrations at high temperatures in the summer months can be caused by heat stress, which reduces DMI. That, in turn, intensifies the degradation of protein in the rumen. Other nutritional problems in summer could be lower water intake, especially during grazing, and mowburn of silage when cows are kept indoors during the entire year. The correlation between MU and temperature in cooler seasons is not easy to explain, however. Month and temperature are connected with the period of grazing and silage preparation, as well as quality of stored forage. The interaction between month and air temperature was used to create classes of month-temperature (MT), which can better reflect the seasonal changes influencing MU concentrations.

Lactation curves for MU concentration in different months with temperatures from $4.1^{\circ} \mathrm{C}$ to $7.0^{\circ} \mathrm{C}$ are shown in Figure 1. They show different levels, for example, observations in April are on average $37.8 \mathrm{mg} \cdot \mathrm{l}^{-1}$ lower than in October. The March and November curves are at similar levels, but in November the curve is slightly more persistent. Interestingly, curves for the same month observed 
at different temperatures also substantially varied in level (Figure 2). In March, differences between average concentrations of MU in consecutive DIM at the lowest and the highest temperatures were rather high (40.4 $\mathrm{mg} \cdot \mathrm{l}^{-1}$ ). Deviations between MU concentrations in MT classes on particular DIM were not equal throughout in the lactation trajectory. The largest difference amounted to $125.2 \mathrm{mg} \cdot \mathrm{l}^{-1}$ and was observed on 118 DIM between MU in August with temperatures ranging from $19.1^{\circ} \mathrm{C}$ to $21.9^{\circ} \mathrm{C}$ $\left(279.9 \mathrm{mg} \cdot \mathrm{l}^{-1}\right)$ and in December with temperatures ranging from $-7.9^{\circ} \mathrm{C}$ to $-5.0^{\circ} \mathrm{C}\left(154.6 \mathrm{mg} \cdot \mathrm{l}^{-1}\right.$, Figure 3). In general, higher curves described higher air temperature, also during the cooler months. It is not easy to understand the mechanism underlying the increase of MU correlated with the temperature increase, but definitely it is unrelated to heat stress. Nonetheless, our results show that when MU is interpreted for feeding management, air temperature should be taken into account not only during summer months.

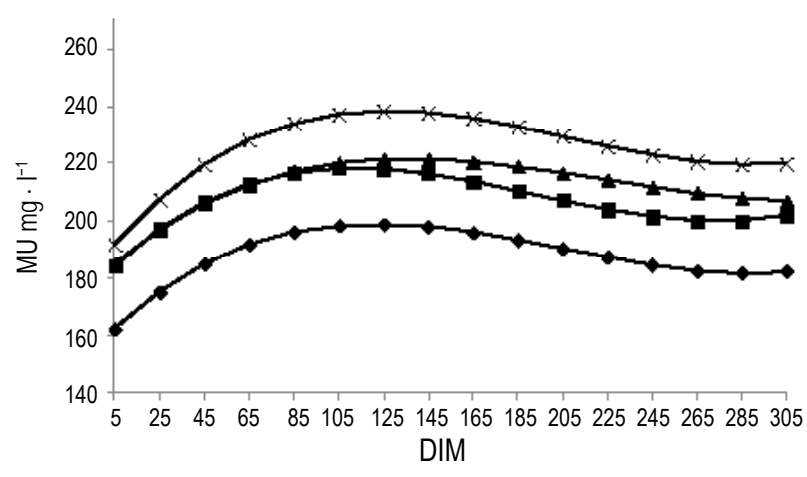

Figure 1. Lactation curves of milk urea concentration for cows in first lactation calved at age of more than 24 months milked in March (घ), April $(\boldsymbol{\nabla})$, October $(\mathrm{x})$ and November $(\boldsymbol{\Lambda})$ with mean temperature form $4.1^{\circ}$ to $7.0^{\circ} \mathrm{C}$

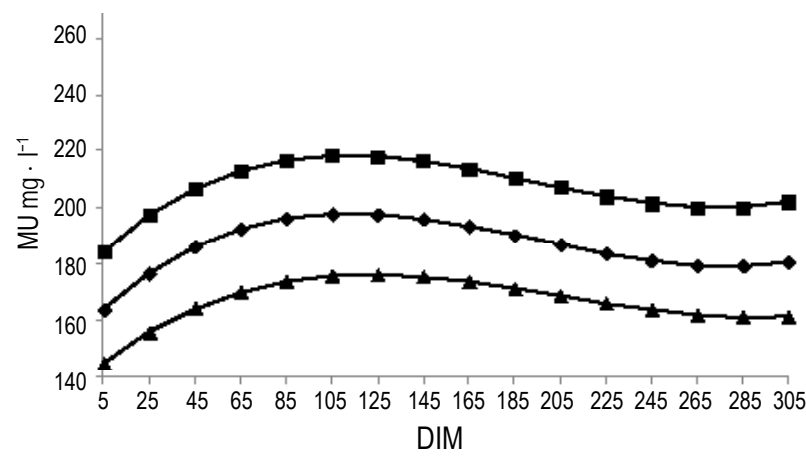

Figure 2. Lactation curves of milk urea concentration for cows in first lactation calved at age of more than 24 months milked in March with mean temperature from $-1.9 \circ$ to $1.0^{\circ}(\boldsymbol{\Lambda})$, from $1.1 \circ$ to $4.0^{\circ}(\bullet)$, from $4.1 \circ$ to $7.0^{\circ} \mathrm{C}(\mathbf{\square})$

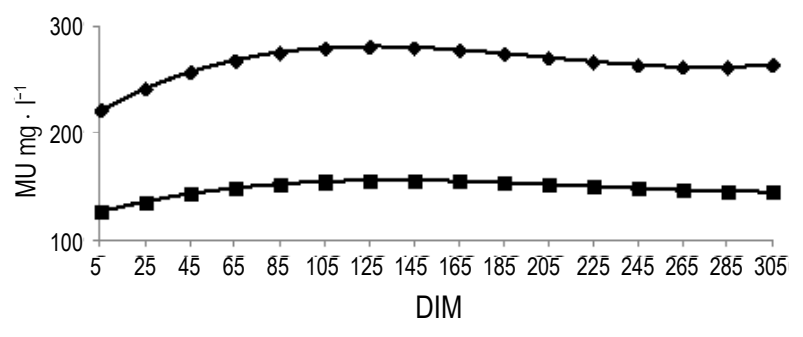

Figure 3. Lactation curves of milk urea concentration for cows in first lactation calved at age of more than 24 months milked in August with mean temperature from $19.1^{\circ}$ to $21.9^{\circ} \mathrm{C}(\downarrow)$ and in December with mean temperature from $-7.9^{\circ}$ to $-5.0^{\circ} \mathrm{C}(\mathbf{\square})$

\section{Effect of herd production level}

Lactation curves for herds with different average milk production (MP) are shown in Figure 4. The mean values of MU concentrations were 206.7 (SD = 102.0), $212.4(\mathrm{SD}=92.9)$ and 236.2 ( $\mathrm{SD}=85.8)$ in low-, medium-, and high-producing herds, respectively. The difference in level of MU was greater for herds with a higher MP, but still lower

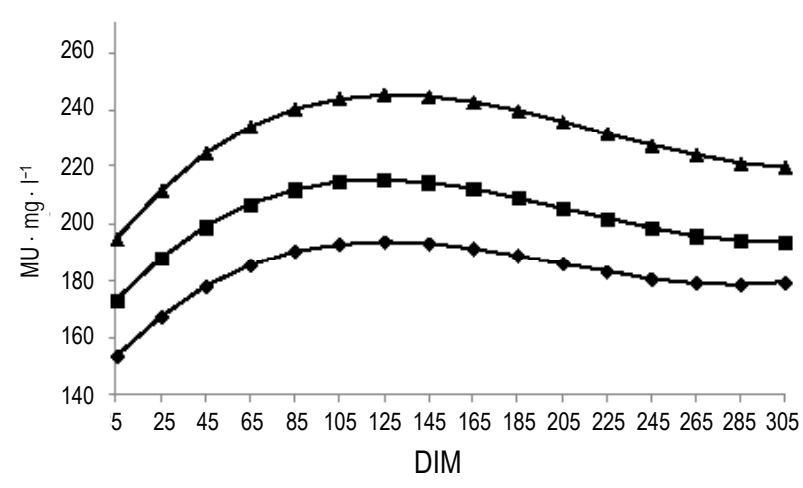

Figure 4. Lactation curves of milk urea concentration for cows in first lactation calved at age of more than 24 months and milked in April (with temperature from $7.1^{\circ}$ to $10.0^{\circ} \mathrm{C}$ ) by classes of herd average daily milk production level ( $\bullet$ low, medium, $\Delta$ high)

than the differences between MU in classes of different temperature. In herds with a lower MP, the standard deviation of MU concentration was higher, which might be a consequence of different feeding systems (grazing, TMR).

This tendency is consistent with the observations of Rajala-Schultz and Saville (2003), but these authors report no association between herd production level and average MUN concentration within production groups, however. In contrast, in our study an increase of $1 \mathrm{~kg}$ in mean daily herd milk production was associated with an increase in the MU concentration by $3.1 \mathrm{mg} \cdot \mathrm{l}^{-1}$ in medium MP and $4.3 \mathrm{mg} \cdot \mathrm{l}^{-1}$ in high MP. Such a correlation was not observed in low PM. The shapes of curves 
for herds with different MP were similar, but curves for herds with high MP had more pointed peaks of lactation. The maximum values were observed between 120 and 130 DIM and amounted to 193.8, 215.4 and $245.4 \mathrm{mg} \cdot \mathrm{l}^{-1}$ for low, medium and high production levels, respectively. The differences between MU concentration in herds with different MP were the highest in mid-lactation and amounted to $51.7 \mathrm{mg} \cdot \mathrm{dl}^{-1}$ in $141 \mathrm{DIM}$ between low and high MP. Our results show that the same concentration of MU can be interpreted differently depending on the average herd milk production and decisions taken on this basis can vary. The lactation curves for herds with different production levels can be used as a reference for herds with a particular production level. Jonker et al. (1998) estimated MUN throughout lactation for cows producing 8000,10000 , or $12000 \mathrm{~kg}$ milk per lactation. As a result, higher levels of curves for cows with higher milk production were obtained. The trend was similar to our results, even though the milk production levels in the Polish population were lower compared with other populations. In high-producing herds, energy deficiency could occur as the result of difficulty in satisfying energy requirements. Another reason for higher MU concentration in herds with a higher MP could be a positive correlation between MU and milk yield at the cow level, which was presented in studies by Jonker et al. (1998) and Johnson and Young (2003). Other researchers found that the MUN concentration increased by about $0.05 \mathrm{mg}$. $\mathrm{dl}^{-1}$ when fat corrected milk yield increased by $1 \mathrm{~kg}$ (Arunvipas et al., 2003; Cao et al., 2010). Only Jonker et al. (1998) reported greater increases in MUN concentration with increases in milk production than in our study, but they investigated herds with higher levels of milk production. Hojman et al. (2004) found a positive correlation between MU concentration and milk yield, but simultaneously observed high producing herds with low MU concentration. They suggested that effective feeding management can stimulate milk production without increasing MU concentration. On the other hand, Wattiaux et al. (2005) observed a constant MUN in primiparous cows yielding less than $43 \mathrm{~kg}$ per day and decreased MUN concentrations when milk production rose over that value. Also Godden et al. (2001) found a negative relationship between $\mathrm{MU}$ and average herd production. The authors explained that the conversion of ammonia to urea reduced the amount of energy available for milk production. It is known, however, that when protein and energy are in balance but their amount is below demand, the concentration of MUN can be moderated, but milk production is low.

\section{Interaction between herd production level and effects related to month and temperature}

Concentration of MU in different MT classes varied and was the most variable in herds with low PM. Differences between extreme values of various seasons (MT) were 107.4, 80.9 and 79.4 for low, medium and high MP, respectively. It is likely that in herds with higher MP values, cows could be fed with TMR throughout the year, which ensures a relatively constant diet composition. As a consequence, in these herds, relatively small changes in MU concentration were observed. A similar tendency was reported by Rajala-Schultz and Savile (2003). In their study, a lesser influence of season on MU concentration in higher producing herds was observed. The MU concentration in summer was the highest for low-producing herds, but lower than in winter and spring for high-producing ones. The authors suggested that this could be the result of lower DMI due to the heat. In our studies, deviations between MU concentration in particular MT for herds with low and high MP were not equal. The highest differences were observed in winter (58.1 $\mathrm{mg} \cdot \mathrm{l}^{-1}$ in January with a temperature from $-7.9^{\circ} \mathrm{C}$ to $-5.0^{\circ} \mathrm{C}$ ), but there were no differences in summer months (July to September) regardless of the temperature class. It is possible that in herds with high-producing cows, some kind of cooling system was installed reducing the effect of temperature. At the same time, herds in which cows were grazing could experience problems with lower water intake. This affects the amount of liquid in the body and influences the MU concentration. We could not confirm our hypotheses due to lack of access to information on nutrition and management.

Interactions between MP and MT can be further studied by analysing selected lactation curves for MU in PMT classes as shown in Figure 5. In some seasons (MT) curves for herds with different MP differed not only in levels, but also in shape, which is visible in February with temperatures ranging from $-4.9^{\circ}$ to $-1.9^{\circ} \mathrm{C}$ (on average $58.8 \mathrm{mg} \cdot \mathrm{l}^{-1}$ lower for low- than for high-producing herds). Curves for low and medium MP were more persistent and the difference between their levels was smaller than between curves for medium and high MP $\left(20.6 \mathrm{mg} \cdot \mathrm{l}^{-1}\right)$. The curves with the highest level, MT classes in particular, were not always showing the highest MP. This was due to the differences in the levels of curves for low MP. In those herds variability was higher and strongly associated with changes in season. Herds with different production levels can 


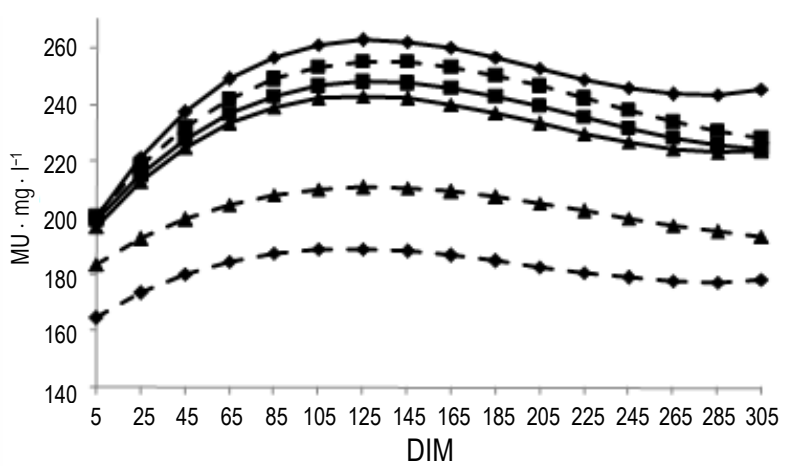

Figure 5. Lactation curves of milk urea concentration for cows in first lactation calved at age of more than 24 months milked in February with temperature from $-4.9^{\circ}$ to $2.0^{\circ} \mathrm{C}$ (dotted line) and August with temperature from $16.1^{\circ}$ to $19.0^{\circ} \mathrm{C}$ (solid line)

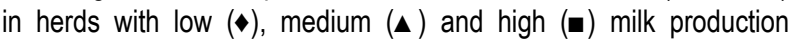

differ in management, including systems of feeding and housing (stabling or grazing). Because of this, cows from herds with low and high MP can react to changes in temperature and months in different ways. For herds with different production levels, standard MU curves should account for month and temperature, especially in low-producing herds, due to the strong impact of seasonal factors.

\section{Conclusions}

It was shown that non-nutritional environmental effects, such as stage of lactation, calendar month, air temperature, average herd daily milk production, and interactions between some of these effects, have an impact on milk urea (MU) concentration. Thus, to avoid wrong management decisions, MU should be analysed taking these factors into account. Furthermore, the optimum value of MU under various environmental conditions can be different. Knowledge about the pattern of lactation curves can improve the effectiveness of MU as a tool for monitoring and correcting dietary composition, usually based on the average MU concentration for cows in four stages of lactation. That will allow more precise evaluation of the extent to which the nutritional needs of cows are satisfied in subsequent stages of lactation. Our results show that variations throughout the year are related not only to changes in the feeding programme. In fact, such an interpretation can be a cause of mistakes.

\section{Acknowledgment}

The authors thank The Polish Federation of Cattle Breeders and Dairy Farmers as well as The Institute of Meteorology and Water Management for access to the datasets.

\section{References}

Arunvipas P., Dohoo I.R., VanLeeuwen J.A., Keefe G.P., 2003. The effect of non-nutritional factors on milk urea nitrogen levels in dairy cows in Prince Edward Island, Canada. Prev. Vet. Med. 59, 83-93

Bastin C., Laloux L., Gillon A., Miglior F., Soyeurt H., Hammami H., Bertozzi C., Gengler N., 2009. Modeling milk urea of Walloon dairy cows in management perspectives. J. Dairy Sci. 92, 3529-3540

Cao Z., Huang W., Wang T., Wang Y., Wen W., Ma M., Li S., 2010. Effects of parity, days in milk, milk production and milk components on milk urea nitrogen in Chinese Holstein. J. Anim. Vet. Adv. 9, 688-695

Godden S.M., Lissemore K.D., Kelton D.F., Leslie K.E., Walton J.S., Lumsden J.H., 2001. Relationships between milk urea concentrations and nutritional management, production, and economic variables in Ontario dairy herds. J. Dairy Sci. 84, 1128-1139

Hojman D., Kroll O., Adin G., Gips M., Hanochi B., Ezra E., 2004. Relationships between milk urea and production, nutrition, and fertility traits in Israeli dairy herds. J. Dairy Sci. 87, 10011011

Jilek F., Řehak D., Volek J., Štipkova M., Němcova E., Fiedlerova M., Rajmon R., Švestkova D., 2006. Effect of herd, parity, stage of lactation and milk yield on urea concentration in milk. Czech J. Anim. Sci. 51, 510-517

Johnson R.G., Young A.J., 2003. The association between milk urea nitrogen and $\mathrm{DHI}$ production variables in Western commercial dairy herds. J. Dairy Sci. 86, 3008-3015

Jonker J.S., Kohn R.A., Erdman R.A., 1998. Using milk urea nitrogen to predict nitrogen excretion and utilization efficiency in lactating dairy cows. J. Dairy Sci. 81, 2681-2692

Miglior F., Sewalem A., Jamrozik J., Lefebvre D.M., Moore R.K., 2006. Analysis of milk urea nitrogen and lactose and their effect on longevity in Canadian dairy cattle. J. Dairy Sci. 89, 4886-4894

Miglior F., Sewalem A., Jamrozik J., Bohmanova J., Lefebvre D.M., Moore R.K., 2007. Genetic analysis of milk urea nitrogen and lactose and their relationships with other production traits in Canadian Holstein cattle. J. Dairy Sci. 90, 2468-2479

Misztal I., Tsuruta S., Strabel T., Auvray B., Druet T., Lee D.H., 2002. BLUF90 and related programs (BGF90). In: Proceedings of the $7^{\text {th }}$ World Congress on Genetics Applied to Livestock Production. Montpellier (France). CD-ROM communication 28-07

Rajala-Schultz P.J., Saville W.J.A., 2003. Sources of variation in milk urea nitrogen in Ohio dairy herds. J. Dairy Sci. 86, 1653-1661

Ramírez J.Y., Cue R.I., MustafaA., Lefebvre D., Wade K., 2008. Factors altering milk urea nitrogen in dairy cattle. In: Department of Animal Science Research Reports, Macdonald Campus of McGill University, pp. 42-47

SAS, 1990. SAS/STAT User's guide, version 6. $4^{\text {th }}$ Edition. SAS Institute Inc., Cary, NC

Stoop W.M., Bovenhuis H., van Arendonk J.A.M., 2007. Genetic parameters for milk urea nitrogen in relation to milk production traits. J. Dairy Sci. 90, 1981-1986

Wattiaux M.A., Nordheim E.V., Crump P., 2005. Statistical evaluation of factors and interactions affecting dairy herd improvement milk urea nitrogen in commercial Midwest dairy herds. J. Dairy Sci. 88, 3020-3035 